2017

\title{
Designing Engaged Scholarship: From Real-World Problems to Research Publications
}

Lars Mathiassen

Georgia State University, lmathiassen@ceprin.org

Follow this and additional works at: https://commons.case.edu/emr

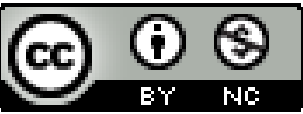

This work is licensed under a Creative Commons Attribution-Noncommercial 4.0 License

\section{Recommended Citation}

Mathiassen, Lars (2017) "Designing Engaged Scholarship: From Real-World Problems to Research Publications," Engaged Management ReView: Vol. 1 : Iss. 1 , Article 2.

Available at: https://doi.org/10.28953/2375-8643.1000

https://commons.case.edu/emr/voll/iss $1 / 2$ 


\section{Designing Engaged Scholarship: From Real-World Problems to Research Publications}

\section{Cover Page Footnote}

Acknowledgements. I would like to thank Mike Chiasson and Matt Germonprez for our research collaboration on style composition in action research publication. I have adapted and used core concepts and ideas from that research as basis for this essay. I would also like to thank the many colleagues and doctoral students with whom I have conducted workshops to help them develop and publish engaged scholarship. These experiences helped me formulate the presented design approach to engaged scholarship publication. Also, many of these good colleagues provided valuable feedback on earlier versions of the essay. 


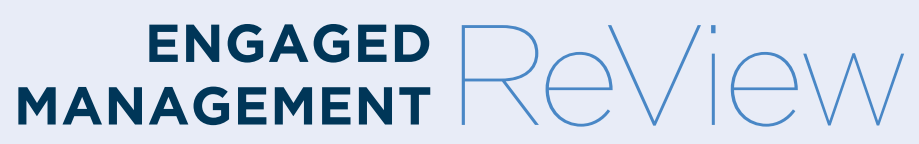

\section{EDITORIAL NOTE}

Mathiassen's essay offers sorely needed practical guidance on how practitionerscholars can successfully design their research and writing resulting in a more effective publication strategy. The paper does not come with a cookie-cutter template of how to publish engaged management scholarship. Such an approach and goal would be contrary to the whole idea of the reflexive, contextualized practitioner-scholar. Rather, it lays out a "design" that practitioner-scholars can use for their research journey; with it, they can align and balance the separate but complementary interests of creating credible and novel research and publishing this research in ways that influence critical stakeholder groups. My hope is that this article guides engaged management scholars to prepare stronger manuscripts for any of the publishing outlets available to them - including Engaged Management ReView. I also hope that the article helps struggling executive doctoral students to better integrate their publication goals and practices to their research journey.

Kalle Lyytinen

\section{Designing Engaged Scholarship: From Real-World Problems to Research Publications}

\author{
Lars Mathiassen \\ Georgia State University
}

\section{ABSTRACT}

Engaged scholarship is a participatory form of research for studying complex realworld problems based on the different perspectives and understandings of key stakeholders. As such, it affords researchers an opportunity to contribute to practical problem solving while also developing new theoretical insights. However, the amount of research methodology available is overwhelming, and moving from real-world problems to research publications is inherently complex and uncertain. Against that backdrop, I offer an approach that can help researchers make sense of and manage this process by designing the key components of a study, designing the resulting publication, and iteratively revising these two designs in light of the problem setting and the relevant literature. The purpose is not to provide a substitute for the use of an appropriate research methodology, nor is the ambition to create a simple and predictable research process. Instead, I suggest that designing and continuously updating two interrelated design documents allows researchers to navigate an inherently complex process by making their research design transparent, by increasing the consistency of their decisions, and by accommodating feedback from collaborators and stakeholders. The approach draws on published research methodology and on my practical experience in coaching engaged scholarship students and researchers. In this essay, I describe and illustrate the approach and offer guiding principles to help you adapt and use it. 


\section{THE CHALLENGE}

Engaged scholarship (Van de Ven, 2007) seeks to bridge the theory-practice gap in profession-oriented disciplines by developing research that contributes both to practical problem solving and to providing new theoretical insights. The idea is to draw on the perspectives and understandings of key stakeholders in real-world problem situations to frame research according to related knowledge areas and, in turn, to leverage theory and empirical findings to help address the problem situation. Van de Ven (2007) defines four different forms of engaged scholarship: Informed basic research is undertaken to describe, explain, or predict a social phenomenon; collaborative basic research is similar but entails a greater sharing of power and collaboration between researchers and stakeholders; design and evaluation research focuses on normative knowledge related to design and evaluation of policies, programs, and models for solving practical problems in a profession; and action research involves intervention to address a problem of a specific client, through which the researcher aims to contribute to academic knowledge. Engaged scholarship might rely on different epistemologies. Also, it might use variance models to focus on causal relationships between antecedents and outcomes, or it might use process models to emphasize how sequences of events unfold over time to produce certain outcomes (Mohr, 1982; Langley et al., 2013). As such, with its core commitment to bridging theory and practice, engaged scholarship allows researchers to draw on an overwhelming variety of relevant research methodologies, including both quantitative and qualitative methods.

Moving from engagement with real-world problems to publication of new knowledge-whether in the form of a dissertation or a journal publication-is a challenging process that involves a "multidirectional network of knowledge creation" (Mohrman and Lawler, 2011). Each problem situation affords different opportunities for anchoring a study in the extant literature, for adopting a mode of inquiry to guide data collection and analysis, for leveraging and developing theory, and for positioning the study to provide new knowledge to the literature, in addition to contributing to practical problem solving. Researchers have to negotiate these multiple choices to produce a coherent, evidence-based argument and, in doing so, to generate a practical and theoretical contribution that is worthy of publication or defendable as a dissertation. Making these decisions before you engage with the problematic situation is not possible. There are simply too many complexities and uncertainties involved. You therefore need to engage based on preliminary decisions and then reconsider issues and adapt decisions as you become increasingly acquainted with the problem situation, with relevant theory, and with opportunities to develop a strong publication.

Against this backdrop, I suggest a design approach to engaged scholarship in which I rely on Herbert Simon's $(1962,1996)$ approach to separating concerns in design and on adaptations of his ideas to management and decision making (Boland and Collopy, 2004; Boland et al., 2006; Frisk et al., 2014). Accordingly, I view engaged scholarship as a creative process in which researchers discover and evaluate different ways to frame and publish their research by iteratively collecting and interpreting knowledge and evidence, exploring and testing ideas, and discovering and evaluating alternatives (Frisk et al., 2014). I suggest that engaged scholarship calls for designing two inter-related documents from the very start: one that expli- cates the key components of the research and one that describes the structure of the resulting publication. These documents should be continually updated and revised until the research has converged toward a stable and consistent design (Figure 1). This approach does not substitute for an appropriate research methodology, nor does it create a simple and predictable research process. Instead, I suggest that designing and continuously updating these two documents makes the research design transparent; it helps researchers to make consistent decisions about the research and the resulting publication; and it affords better opportunities to elicit and adapt to feedback from collaborators and stakeholders during the research. As such, the proposed design approach enhances researchers' capability to make sense of and manage an engaged research process that is inherently complex and uncertain.

In the following, I draw on published research methodology (Checkland, 1991; Day, 1991; Mathiassen et al., 2012) to show how to design the two documents and how to leverage them to publish the results. I illustrate the approach and conclude with practical principles for designing engaged scholarship. My experiences from coaching students and researchers suggest that the proposed design approach, as a complementary research method, is easy to learn, requires little effort, affords opportunities to acquire valuable feedback from others, and helps to generate a coherent and persuasive research publication. Moreover, because engaged scholarship is often organized in close collaboration between researchers

Figure 1: Designing Engaged Scholarship

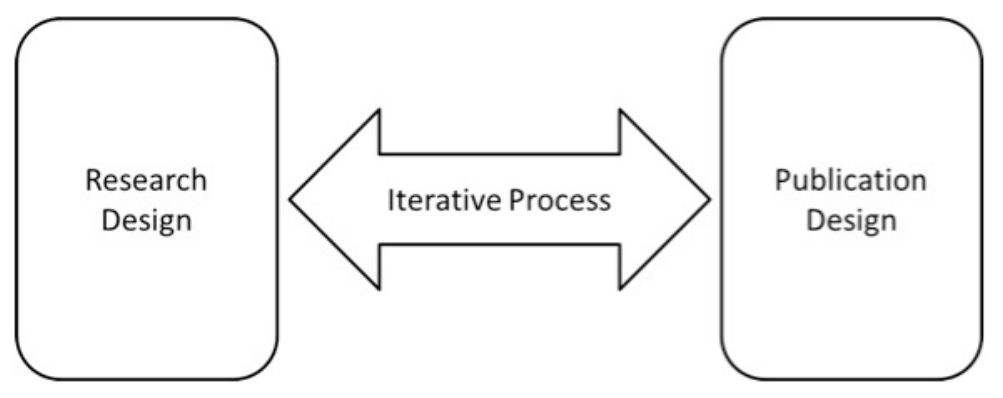


Figure 2: A Generic Structure of Engaged Scholarship Study

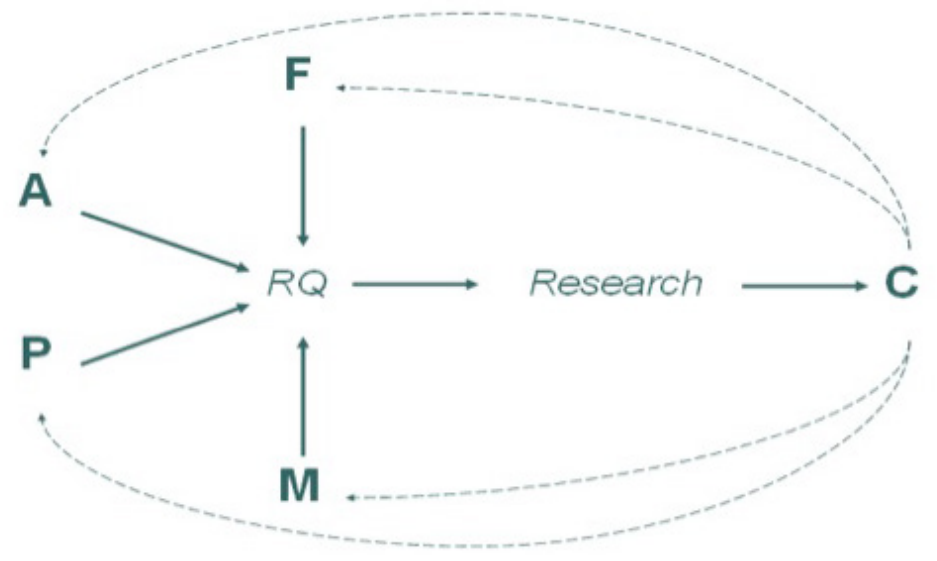

and practitioners (Bartunek and Louis, 1996; Amabile et al., 2001; Mathiassen and Sandberg, 2013), the approach can help to establish and maintain a shared understanding of key decisions among participants who have diverse backgrounds and interests.

\section{RESEARCH DESIGN}

Drawing on Checkland's general model of scientific inquiry (1991) and subsequent elaborations (McKay and Marshall, 2001; Mathiassen et al., 2012), Figure 2 captures a generic structure of an engaged scholarship study. Moving from left to right, the components and relationships are as follows: The research question (RQ) is raised based on a real-world problematic situation $(\mathrm{P})$ and a related area of concern in the literature (A); addressing the RQ involves collecting and analyzing empirical data drawing on a method of inquiry (M) and possibly on a conceptual framework (F); eventually, this leads to contributions to the $P\left(C_{P}\right)$ and the $A\left(C_{A}\right)$ and possibly to a new or developed $F\left(C_{F}\right)$ or an enhanced $M$ $\left(C_{M}\right)$. In the following paragraphs, I detail each component as summarized in Table 1.

A defining characteristic of engaged scholarship is that it draws on the perspectives of key stakeholders in a real-world problem situation (P) and aims to develop knowledge that might help address it (Table 1). As the foundations for their re- search design, researchers must articulate $P$, how they envision engaging with relevant stakeholders, what kinds of data are readily available, and the ways in which they intend to contribute back to P. Such considerations provide early indications of whether the intent is informed basic research, collaborative basic research, design and evaluation research, or action research. The literature offers valuable guidance on how to approach and leverage $P$ in the research (Edmondson, 2011; Van de Ven, 2007). Although the design of a study does not necessarily start out from a specific problem, anchoring the research on a relevant type of $P$ is what makes the research "engaged." As an exemplar publication, Singh et al. (2010) is based on engaged research into the situations rural communities face as they seek to leverage telehealth solutions in response to the lack of medical expertise and requisite health services (Table 1). The paper is co-authored by Rajendra Singh and me with expertise in digital innovation and two telehealth researchers with medical backgrounds. One of them, Max Stachura, had for several years collaborated closely with a rural community to help them leverage telehealth technology. Building on this close relationship, we visited the area, observed telehealth practices, and interviewed citizens, nurses, and managers at the local health institution, doctors from partnering hospitals that provided services to the community, and various technical people who had been part of the process over the past 20 years. From the very start, the case stood out as an unusual example of how diverse stakeholders in a rural community came together to successfully adopt and implement telehealth, thereby significantly expanding the availability of health services to the local population. We had studied different types of telehealth implementations, and we knew that insights from this longitudinal case study could make new contributions to the literature.

While $P$ represents a real-world setting, A represents some area of concern in the literature that relates to $\mathrm{P}$. For any $\mathrm{P}$, several options are always available for articulating a relevant $A$. Moreover, $P$ might not relate to one specific $A$, but to two or more. Hence, positioning new research vis-à-vis the extant literature is a complex task that involves considering multiple areas of research in the literature; making judgements about which ones are better suited for the new study; and possibly combining multiple areas as backdrop for the new research (Huff, 1999, chapter 2). Designing a suitable $A$ requires review of the literature with a focus on whether you can construct an opportunity to make a contribution to that literature, based on your engagement with P (Locke and Golden-Biddle, 1997; Golden-Biddle and Locke, 2007). In addition to having an interest in $A$ or seeing the relevance of $A$ for $P$, researchers must identify gaps or problematic assumptions in the literature about A (Alvesson and Sandberg, 2011) that can be addressed by developing a strong contribution to that literature $\left(C_{A}\right)$ through an engagement with $P$. Although Singh et al.'s (2010) focus on the literature regarding adoption of telehealth in rural institutions as A appears obvious (Table 1), we seriously considered another, equally attractive option: namely, focusing the research on technological innovation in organizations. This choice would have pushed telehealth into the background and instead focused on the more general discourse on technological innovation. However, a review of the literature on telehealth in health services research revealed ample opportunity to make a significant contribution, and we therefore kept our focus on 
Table 1: Components of Engaged Scholarship Research

\begin{tabular}{|c|c|c|}
\hline Component & Definition & Example (Singh et al., 2010) \\
\hline$P$ & $\begin{array}{l}\text { The problem setting represents } \\
\text { people's concerns in a real-world } \\
\text { problematic situation. }\end{array}$ & $\begin{array}{l}\text { Rural areas lack requisite access } \\
\text { to medical expertise and healthcare } \\
\text { services. Although telehealth solutions } \\
\text { can help address this issue, rural health } \\
\text { institutions typically don't have the } \\
\text { resources and capabilities required to } \\
\text { adopt them. }\end{array}$ \\
\hline A & $\begin{array}{l}\text { The area of concern represents } \\
\text { some body of knowledge in the } \\
\text { literature that relates to } P \text {. }\end{array}$ & $\begin{array}{l}\text { Adoption of telehealth in rural } \\
\text { institutions. }\end{array}$ \\
\hline $\mathrm{F}$ & $\begin{array}{l}\text { The conceptual framing } \\
\text { helps structure collection and } \\
\text { analyses of data from } P \text { to } \\
\text { answer RQ; } F_{A} \text { draws on concepts } \\
\text { from } A \text {, whereas } \\
F_{1} \text { draws on concepts } \\
\text { independent of } A \text {. }\end{array}$ & $\begin{array}{l}\text { Fl: Punctuated equilibrium theory } \\
\text { (Gersick, 1991). } \\
\text { F: Episode-encounter process model } \\
\text { (Newman and Robey, 1992). }\end{array}$ \\
\hline M & $\begin{array}{l}\text { The method details the approach } \\
\text { to empirical inquiry, specifically } \\
\text { to data collection and analysis. }\end{array}$ & $\begin{array}{l}\text { Longitudinal, qualitative case study } \\
\text { of how a rural health district } \\
\text { successfully adopted telehealth } \\
\text { as a core part of its operation over } \\
\text { a } 20 \text {-year period. }\end{array}$ \\
\hline $\mathrm{RQ}$ & $\begin{array}{l}\text { The research question relates } \\
\text { to } P \text {, opens for research into } A \text {, } \\
\text { and helps ensure the research } \\
\text { design is coherent and } \\
\text { consistent. }\end{array}$ & $\begin{array}{l}\text { How can rural public health institutions } \\
\text { sustainably adopt telehealth } \\
\text { innovations? }\end{array}$ \\
\hline C & $\begin{array}{l}\text { Contributions influence } \mathrm{P} \text { and } \mathrm{A} \text {, } \\
\text { and possibly also } \mathrm{F} \text { and } \mathrm{M} \text {. }\end{array}$ & $\begin{array}{l}\text { Cp: Lessons for how managers can } \\
\text { create a path toward sustainable } \\
\text { telehealth innovation in rural } \\
\text { institutions. } \\
\text { C }_{\text {A }} \text { A detailed empirical account of a } \\
\text { successful rural telehealth innovation, } \\
\text { including a grounded process model } \\
\text { that describes how the innovation } \\
\text { became sustainable and how actors } \\
\text { addressed key challenges. }\end{array}$ \\
\hline
\end{tabular}

Note: Adapted from (Mathiassen et al., 2012).

the literature on telehealth innovation in rural institutions.

The choice of how to frame the argument (F) helps guide the data collection, it serves as foundation for data analyses, and it is the key intellectual vehicle for answering the RQ to develop a contribution (C) (Table 1). Researchers have many different options for framing data collection and anal- ysis, including adopting a grounded approach without pre-established concepts (Glaser and Strauss, 1977); relying on concepts from the literature on $A\left(F_{A}\right)_{i}$ and relying on concepts that are independent of $A\left(F_{1}\right)$. In qualitative studies, researchers typically adopt a grounded approach or articulate $\mathrm{F}$ as an analytical framework of concepts and some underlying theory. In quantitative studies, re- search typically draws on relevant theory to articulate a model of related constructs and to generate hypotheses of causal relationships. The choice of conceptual framing has important implications for researchers' ability to engage in further theory building based on the empirical material and on whether they adopt an inductive, deductive, or abductive approach (Shepherd and Sutcliffe, 2011). In any case, the chosen analytical approach should allow for leveraging the available data from $\mathrm{P}$ to develop findings that realize the identified opportunity to make a contribution to A. In Singh et al. (2010), the conceptual framework combines classical punctuated equilibrium theory (Gersick, 1991) with a specific process model that distinguishes between brief encounters of disruption and the longer episodes of evolution that follow them (Newman and Robey, 1992). We had several reasons for this choice of Fl: (1) Our engagement with the many stakeholders revealed a process involving many serious disruptions that proved instrumental in explaining the rural institution's successful telehealth innovation path; (2) longitudinal process models based on punctuated equilibrium theory had not yet been applied in the literature on rural telehealth innovation; and (3) Rajendra Singh and I were very familiar with and had previously used the adopted $\mathrm{Fl}$.

An abundance of research methods ( $M$ ) are available to guide engaged scholarship research (Van de Ven, 2007, chapters 1 and 2 ), and the challenge is to select a specific $\mathrm{M}$, or a variant thereof, that can draw on available data from $\mathrm{P}$ to answer the RQ. Moreover, researchers need to have, or be able to develop, the requisite skills to apply $\mathrm{M}$ to their study. Moving through the various components of the research design reveals with increasing clarity how all components are related and highly interdependent, and that the overarching challenge is to arrive at a consistent and useful design. The important perspective-not only in relation to the choice of $\mathrm{M}$, but in all relationships-is to focus on the central role of the RQ and to ensure that the different components constitute a coherent and consistent research design that 
makes a sufficient contribution to both $P$ and A. In Singh et al. (2010), the study is based on a longitudinal, qualitative case study design with retrospective analyses of the events that shaped the path toward successful rural telehealth innovation over a 20 -year period. As such, it exemplifies engaged scholarship using informed basic research by asking a "how" question consistent with the choice of a case study design (Yin, 2009).

The contribution (C) of the research design is the final critical factor. Although the other components must be well designed and executed as a prerequisite for publication, the quality and solidity of the C component ultimately determines whether a study is defendable and can be accepted for publication. Researchers need to make a difference, articulate that difference, and provide convincing evidence to support it. All engaged scholarship efforts should involve a contribution to the real-world problem $\left(C_{P}\right)$ and to the area of concern in the literature $\left(C_{A}\right)$; additional contributions to the conceptual framing $\left(\mathrm{C}_{\mathrm{F}}\right)$ or to the research method $\left(C_{M}\right)$ are more rare. In fact, simpler designs with focused contributions are easier to develop and often more convincing to read. Singh et al. (2010) rely on such a straightforward design with contributions to $P$ and $A$ (Table 1). The paper offers actionable knowledge on how managers in rural institutions can create a path toward sustainable telehealth innovation $\left(C_{p}\right)$; it also offers a detailed empirical account of a rural telehealth innovation - including a grounded process model-that describes how the innovation became sustainable and how actors addressed key challenges $\left(C_{A}\right)$. These contributions draw on data from $P$; they were developed by analyzing the data collected via $M$ through the lens of $F$; and, they offer interrelated responses to the RQ. As such, the $\mathrm{RQ}$ binds the research design together into a coherent and consistent whole.

Although a particular logic defines the relationships between the various components of the research design (Figure 2), a "best sequence" in which to articulate them generally does not exist. The process of designing research is-like any design process-highly iterative, moving back and forth between different options for each component and constantly checking for overall consistency and opportunity to develop a solid contribution until the research has converged toward a stable and consistent design. Table 2 provides a template to support this creative process. In addition to the components already described, the template includes the target journal and the title of the research. The target journal defines the audience and the conversation in which the writing participates (Huff, 2009, chapter 1). Possible target journals can be identified based on where literature on the area of concern (A) is published and the publication must then be written based on a careful analysis of the particular style of the selected journal. One factor to consider is whether recent publications in the journal have used the same or similar methodology as the research being constructed.

The title expresses the essence of the research design, with emphasis on the contribution (C). Specifying the research design (the third column of Table 2 ) offers a roadmap to the activities of the engaged study, and it allows for coordinating the perspectives and directions of research colleagues and other stakeholders from the very start of the research. The problem situation $(P)$ defines the context; the area of concern (A) is the literature reviewed to construct an opportunity to make a contribution; the conceptual or analytical frame-

\section{Table 2: Template for Research Design}

\begin{tabular}{|c|c|c|}
\hline Component & Definition & Specification \\
\hline Journal & $\begin{array}{l}\text { The target journal defines the } \\
\text { audience for the research and the } \\
\text { conversation in which the work } \\
\text { participates. }\end{array}$ & \\
\hline Title & $\begin{array}{l}\text { The title expresses the essence of } \\
\text { the research design, with emphasis } \\
\text { on } C \text {. }\end{array}$ & \\
\hline$P$ & $\begin{array}{l}\text { The problem setting represents } \\
\text { people's concerns in a real-world } \\
\text { problematic situation. }\end{array}$ & \\
\hline$A$ & $\begin{array}{l}\text { The area of concern represents } \\
\text { some body of knowledge in the } \\
\text { literature that relates to P. }\end{array}$ & \\
\hline $\mathrm{F}$ & $\begin{array}{l}\text { The conceptual framing helps } \\
\text { structure collection and analyses of } \\
\text { data from } P \text { to answer RQ; FA draws } \\
\text { on concepts from A, whereas FI } \\
\text { draws on concepts independent of } \\
\text { A. }\end{array}$ & \\
\hline$M$ & $\begin{array}{l}\text { The method details the approach to } \\
\text { empirical inquiry, specifically to data } \\
\text { collection and analysis. }\end{array}$ & \\
\hline $\mathrm{RQ}$ & $\begin{array}{l}\text { The research question relates to } P_{1} \\
\text { opens for research into } A \text {, and helps } \\
\text { ensure the research design is } \\
\text { coherent and consistent. }\end{array}$ & \\
\hline C & $\begin{array}{l}\text { Contributions influence } \mathrm{P} \text { and } \mathrm{A} \text {, and } \\
\text { possibly also } \mathrm{F} \text { and } \mathrm{M} \text {. }\end{array}$ & \\
\hline
\end{tabular}


work $(F)$ is the means for developing the intellectual instruments for data collection and analysis, unless a grounded approach (Glaser and Strauss, 1976) is planned; and the research method $(M)$ both supports the engagement with $\mathrm{P}$ and the development of C. Although these efforts eventually result in a research publication worthy of peer review or a dissertation worthy of public scrutiny, the path from research design to such a publication is not straightforward. The question, then, is how to design a research publication that accurately and adequately conveys the research design (Figure 1).

\section{PUBLICATION DESIGN}

Drawing on research into scientific writing (Day, 1971, 1991; Gopen and Swan, 1990) and on classical argumentation theory (Rottenberg and Winchell, 2005), Mathiassen et al. (2012) reviewed action research publications in leading Information Systems journals to reveal the different ways in which authors present their research and argue for contribution. The approach proposed here adapts their work into a generic structure for engaged scholarship publication (Table 3). The adaptation is feasible because the generic structure relies on general theory regarding argumentation and scientific publication. Action research also is one of the four basic forms of engaged scholarship, so adapting the structure simply involves removing the specifics on how action researchers intervene in a problematic situation (P). Note that different genres of writing are used across different research areas and between academic and practitioner journals. Journals typically construct guidelines for authors to define specific requirements for publication; also, academic journals typically emphasize detailed elaboration of existing literature, of research method, and of empirical findings through a rigorous style of writing, whereas practitioner journals emphasize relevant insights for practice and an engaging style of writing. Thus, the publication structure in Figure 3 must be adapted to the situation at hand. Nevertheless, it provides an explicit mapping of a research design onto a generic publication structure, which researchers can then easily adapt to specific journal traditions and target audiences. As such, it provides a path for moving from an initial research design to a first design of the resulting research publication.

Despite their many variants, engaged scholarship publications typically follow a basic style. The title expresses the essence of the research, with particular emphasis on its contribution. The abstract offers a condensed account of the argument being presented by mentioning all the components in the research design and the underlying logic that binds them together (Figure 2). The introduction elaborates on the abstract by motivating the research design and its key components, as well as the basic argument for contribution. Thus, while the abstract reveals what the com- ponents of the research design are, the introduction elaborates whyeach component was chosen and how they together constitute a coherent and interesting design. The title, the abstract, and the introduction give readers a sense of the presented research and what they can learn from reading the full publication. The rest of the publication then details each component of the research design and provides the evidence and arguments required to substantiate the contribution. This structuring helps readers quickly get a sense of the research and, if necessary, navigate to find details of particular interest.

The introduction presents all key components of the research-P, A, F, M, C, and $\mathrm{RQ}$ - as a condensed argument. It starts with motivations for the research into $A$ and the opportunity to make a contribution to $A$ by investigating $R Q$; continues

Table 3: Generic Structure for Engaged Scholarship Publication

\begin{tabular}{|c|c|}
\hline Section & Definition \\
\hline Title & Express the essence of the research with emphasis on contribution (C). \\
\hline Abstract & $\begin{array}{l}\text { Provide the basic argument based on problematic situation }(P) \text {, area of } \\
\text { concern }(A) \text {, conceptual framing }(F) \text {, research method }(M) \text {, and } C \text {. }\end{array}$ \\
\hline Introduction & $\begin{array}{l}\text { Introduce } A \text { and the motivation for the study. Introduce } \mathrm{P}, \mathrm{F} \text {, and } \mathrm{M} \text { as } \\
\text { appropriate for addressing the RQ. State principal results by making clear } \\
\text { how } \mathrm{C} \text { contributes to } \mathrm{P} \text { and } \mathrm{A} \text {. }\end{array}$ \\
\hline Background & $\begin{array}{l}\text { Present a review of extant literature on A. Substantiate the motivation for } \\
\text { the study by evaluating what we know and don't know about A. Construct } \\
\text { and articulate the opportunity to make a contribution and substantiate the } \\
\text { choice of the RQ. }\end{array}$ \\
\hline Framing & $\begin{array}{l}\text { Introduce and argue for an existing, revised, or developed } F\left(F A \text { and } F_{1}\right) \text { as a } \\
\text { means for structuring and supporting data collection and analysis. }\end{array}$ \\
\hline Methods & $\begin{array}{l}\text { Describe and argue for M. Introduce } \mathrm{P} \text { to provide context for analysis. } \\
\text { Detail and argue for approach to data collection and analysis to respond to } \\
\text { RQ. }\end{array}$ \\
\hline Results & $\begin{array}{l}\text { Present results of data analysis based on F, following } \mathrm{M} \text {, and to help } \\
\text { answer RQ. Focus on appropriate structuring of analysis and use tables } \\
\text { and graphs. Establish empirical foundation to make contribution. }\end{array}$ \\
\hline Discussion & $\begin{array}{l}\text { Explain and argue for contribution to } \mathrm{P}\left(\mathrm{C}_{\mathrm{P}}\right) \text { and } \mathrm{A}\left(\mathrm{C}_{\mathrm{A}}\right) \text { as response to } \mathrm{RQ} \text {, } \\
\text { based on results and background literature. Don't just repeat results. } \\
\text { Discuss relationships to literature, explain conclusions with evidence for } \\
\text { each conclusion, provide alternative explanations, and state theoretical } \\
\text { and practical implications. }\end{array}$ \\
\hline
\end{tabular}

Note: Adapted from (Mathiassen et al., 2012). 
with the engagement with $P$ and the adoption of $\mathrm{F}$ and $\mathrm{M}$ as appropriate approaches for addressing RQ; and reveals the consequential contributions to the problem setting $\left(C_{P}\right)$ and the area of concern $\left(C_{A}\right)$, and possibly to the conceptual framing $\left(C_{F}\right)$ or research method $\left(C_{M}\right)$.

To motivate the RQ, the background section provides a review of the literature about $A$, what already is known that is relevant to the study at hand, and what is not known or challenged. The section elaborates and substantiates what has already been mentioned briefly in the abstract and introduction. In the overall argument, it serves the very important role of identifying the opportunity to make a contribution to the literature, beyond the contributions the research makes to the specific problem setting. A key insight from the work of Golden-Biddle and Locke $(1997,2007)$ is that identifying gaps and problematic assumptions (Alvesson and Sandberg, 2011) in a particular stream of literature requires actively engaging in interpretation of the literature-not simply reading it. Researchers must consider what is relevant for their own study and what is special or unique about their engagement with $\mathrm{P}$. Only then can they think about appropriate conceptual framings (F) and research methods (M) that allow for convincingly presenting what is known and constructing an opportunity to make a contribution to knowledge.

Following the background section, the next two sections present the conceptual framing (F) and research method (M), together with the reasons for choosing them. The framing section introduces an existing, revised, or developed $F$ and argues that it offers an appropriate means for structuring and supporting data collection and analysis in response to RQ. Although researchers typically incorporate and rely on some established concepts about $A\left(F_{A}\right)$, adding concepts or theories independent of $A\left(F_{1}\right)$ can often produce a line of inquiry that leads to new insights into $A$. In structuring the framing section, being aware of differences in style between qualitative research-which em- phasizes the concepts and relationships used to make sense of data - and quantitative research-which focuses on models of related constructs with hypotheses about causal relationships-is important.

The methods section then describes and supports the choice for the particular research methods used. It introduces the problem setting $(P)$ to provide context for the analysis, and it details and argues for the selected approach to data collection and analysis in response to RQ. Important interdependences exist between the framing and the methods sections, in that concepts and relationships from the framing section provide the intellectual apparatus for executing the methods to establish a strong empirical foundation for making a contribution.

The discussion section is probably the most important section because its purpose is to explain and argue for contributions to the problem setting and the area of concern and potentially to the conceptual framing or research method used. It also is the most difficult section to write. The section typically starts with a brief recap of the argument as laid out in the introduction. It then explains the contribution to $A$ by reviewing the key empirical findings from the results section and discussing how they relate to extant literature about $A$ from the background section: how the findings might corroborate, contradict, or challenge what we already know and how they add significant new insights about A. Such discussion might be restricted to highlighting important empirical insights, but it might also contribute new concepts and relationships about $A$ $\left(F_{A}\right)$. Research publications that present new concepts or theory about A might do so in different ways: (1) in the framing section and subsequently in the results section; (2) in the discussion section, based on existing concepts and relations in the framing section and empirical insights from the results section; or (3) using a combination of both these styles. Often, a contribution to $P$ is presented as implications for both practice and theory toward the end of the discussion section, as a re- quired add-on. Instead, reporting on engaged scholarship should seriously attempt to bridge theory and practice by including evidence of contributions to $\mathrm{P}$ (as in the case of action research) and actionable principles for practice (as in the case of design and evaluation research). As such, researchers might choose to develop theory that goes beyond understanding, explanation, and prediction to include prescription for practice (Gregor, 2006).

To illustrate adaptation of the generic publication structure, we return to Singh et al. (2010), which appeared in Health Services Research, a top academic journal in health management. The mission of Health Services Research is "to enhance knowledge and understanding of the financing, organization, delivery, and outcomes of health services through publication of thoughtful, timely, rigorously conducted, state-ofthe-art research and thinking." Full-length research articles in this journal typically follow a particular structure, and they are limited to 4,800 words, excluding abstract, references, tables, and figures. Given these characteristics, we adapted the generic publication design as detailed in Table 4. The most important changes are: (1) . packaging the conceptual framing $(F)$ and research method $(\mathrm{M})$ into the research design and method sections; (2) presenting the theoretical contributions to the area of concern $\left(C_{A}\right)$ as part of results; and (3) strongly emphasizing the discussion of lessons for practice $\left(C_{P}\right)$ and the practical value of the research. As such, the adaptation was simple, and it helped us design a rich, but quite comprehensive, publication aligned with journal requirements.

\section{DEVELOPING THE PUBLICATION}

Keeping in mind that publishing engaged scholarship is a complex and uncertain endeavor, researchers must allow their research design document (Table 2) and their publication design document (Table 3) to iteratively shape each other until the research has converged toward a stable and consistent design (Figure 1). The initial 
Table 4: Adaptation of Generic Publication Structure in Singh et al. (2010)

\begin{tabular}{|l|l|}
\hline Publication Structure & Adaptation of Generic Structure \\
\hline Introduction & Introduction section \\
\hline Literature Review & Background section \\
\hline Research Design & Framing section and case study design from methods section \\
\hline Method & Data collection and analysis from methods section \\
\hline Results & Results section and contribution to $A\left(C_{A}\right)$ from discussion section \\
\hline Discussion & Contribution to $P\left(C_{P}\right)$ from discussion section \\
\hline Conclusion & Limitations and practical value \\
\hline
\end{tabular}

designs necessarily change with problem setting (P) engagement, with reviewing the literature on the area of concern (A), and with the analysis of data. The writing of the publication is also a creative activity that can involve changes in both the publication design and the research design (Huff, 1999).

For several reasons, early and intentional design of the research and the publication and continuous revision of these documents eases the development of a strong publication. First, carefully attending to the research and publication designs leads more quickly and with less iteration toward a consistent and coherent argument. Second, such designs serve as important sense-making devices that identify significant new insights and deviations from earlier decisions during the research process. Third, the two design documents allow for focused communication about the project, both to coordinate with possible co-authors and to obtain valuable feedback on the ideas being communicated from other researchers and stakeholders. In addition, being explicit about a research design and related publication structure can be especially useful to help establish and develop close collaboration between practitioners and researchers as a typical approach to engaged scholarship (Bartunek and Louis, 1996; Amabile et al., 2001). Finally, creating and keeping the two design documents updated requires relatively little effort and the potential gain from using them significantly outweighs the cost of developing and maintaining them.

Figure 3 illustrates the iterative process of developing a research publication. The process follows the Simonian approach to design, in which the researcher constantly interacts with her or his environment (Simon, 1962, 1996), discussing the project with collaborators and colleagues, engaging with the problem setting $(P)$, studying the literature on the area of concern (A), collecting and analyzing data, and writing drafts of the publication. Through these interactions, researchers collect and interpret knowledge and evidence, explore and test ideas, and discover and evaluate alternatives (Boland and Collopy, 2004; Boland et al., 2006; Frisk et al., 2014). At the core of this iterative process is the research design, which serves as foundation for developing different representations of the publication. Meanwhile, the experience of developing representations of the publication and the feedback received on them trigger revisions to and improvements of the research design. The starting point is the publication design, based on Table 3, followed by the extended abstract, which details the argument and structure of the paper. Iterations between these elements result in development of the full paper, and eventually a published paper or defended dissertation. The entire process then potentially points toward additional publications that stem from the engagement with $P$.
Figure 3: Iterative Development of the Publication

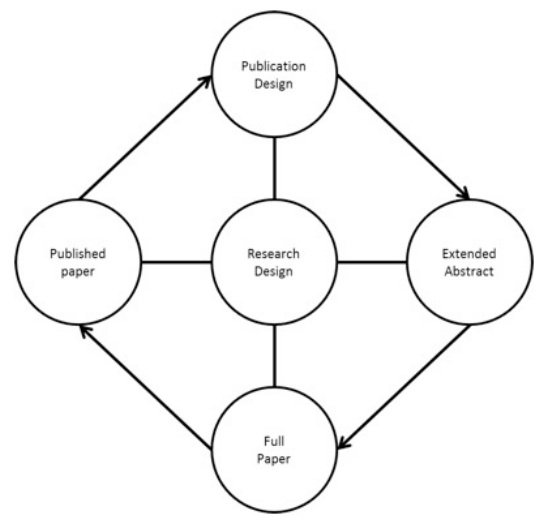

The extended abstract fleshes out the initial research design (Table 2 ) into a two- to four-page document that includes the following elements: 1) title; 2) target journal; 3) full abstract of 200-400 words; 4) publication structure with bullet point content for each section; and 5) key references. The publication structure (4) adapts the generic structure (Table 3 ) to lay out the detailed argument of the publication, consistent with the full-text abstract (3) and target journal requirements and traditions. The extended abstract articulates the flow of the argument and presents the research in a comprehensive form with sufficient detail so that other researchers might quickly review and critique it. As such, the extended abstract also generates opportunities to adjust the publication design and research design before investing too many resources in actually writing and critiquing the text. Moreover, the extended abstract establishes a solid foundation for writing the publication (Huff, 1999) and for coordinating with possible research collaborators.

Conceptualizing the publication in three parts can be helpful: foundation, findings, and contributions. The foundation consists of the title, abstract, introduction, background, framing, and methods sections (Table 3). These sections can be developed both before and during data collection. The findings consists of the results section presenting the analysis of the data. Finally, the contributions are pre- 
sented and argued in the discussion section drawing on the foundation and the findings.

The full version of a potential publication often is the product of interactions with co-authors and others who provide feedback - whether readers or listeners who have heard the publication presented at seminars and workshops. Engaging in such opportunities for feedback and taking it into account allows for a stronger publication, whether submitted for peer review or as a dissertation defense. Researchers thus can identify and remove superfluous material, improve the consistency of their argument, and present a more persuasive contribution. For journal submissions, editors and reviewers might require researchers to undertake significant reworking, rewriting, or fresh analysis of the data; however, if the contribution is not clear, rejection is more likely. All feedback, both before and after submission, can help eventually to get the research published.

In the process toward publication of Singh et al. (2010), we arranged a one-day workshop between the four authors after all the data were collected and data analysis had begun. At that point, we had an initial research design (Table 2 ) and had decided to seek publication in a health management journal. Singh had reviewed different journal options, their rankings, and the kinds of research published in each journal. We discussed this material at the workshop and decided to submit the work to Health Services Research because of its high ranking, a format that was appropriate to present our research, and a track record of publishing qualitative studies like ours. The workshop resulted in an extended abstract for the paper and a plan to develop a first full version. Singh and I did the majority of the writing while the other two authors provided detailed feedback and suggestions on all parts of the paper. After we had generated a suitable first version, we sent the publication to key stakeholders involved in the case and asked them to comment on our presentation and analyses. This process led to several adjust- ments and to permission to submit the material for publication, with full disclosure of the case context. The publication went through two rounds of revision before being published in Health Services Research.

Afterward, Singh and I continued to work on the empirical material, this time seeking to develop new theory on technological innovation in organizations. During this process, we engaged a colleague, Abhay Mishra, who had similar interests, as the third author. We pushed telehealth into the background and focused on theorizing how organizations constitute innovation paths over time as they leverage new technologies. This revised area of concern (A) led to a different research design based on the same empirical material and aimed at contributing to the theory of path dependence (Arthur, 1989; David, 1985) and path creation (Garud and Karnøe, 2001) in technological innovation. As summarized in Table 5, this research design is quite different from the initial design shown in Table 1. The development of this second publication went through six rounds of review and revision at three different journals before final publication. As such, this second publication illustrates the significant challenges involved in getting research published, including finding an appropriate journal, adapting to its specific style and tradition, managing emotional reactions to critique of the research, rethinking and changing the initial argument, and spending significant resources to develop detailed responses to several rounds of feedback from editors and reviewers.

\section{PRACTICAL PRINCIPLES}

The purpose of this essay has been to offer an approach for making sense of and managing the complex and uncertain process of moving from real-world problems to research publications in engaged scholarship. The approach is based on the idea that development of a research publication is a creative process (Figure 1) in which both the research (Table 2) and the publication (Table 3) are "designed," and such designing allows for different representations of the publication over time (Figure 3). Moreover, it emphasizes the importance of making the research design and publication structure explicit at an early stage in the process and moving iteratively between these two documents through engagement with the problem setting and extant literature. In the previous sections, I have provided the underlying rationale for the approach, laid out its different components, and illustrated with one of my own publication experiences. The following summarized principles of the approach can help researchers adapt and use it in their own engaged scholarship:

- Ensure problem setting engagement. Solid relationships to key stakeholders are necessary to ensure effective data collection and to anchor the research in real-world problems and perspectives. Researchers therefore should ensure appropriate access to the problem setting $(P)$ before they decide to engage. When relationships to key stakeholders involve significant uncertainties, they generally should consider other options. Solid anchoring in a real-world problem setting defines and drives engaged scholarship.

- Construct the opportunity to contribute to the literature. For engaged scholarship to be publishable, it must focus on an appropriate area of concern $(A)$ in the academic literature. The area must be relevant to the problem setting so that knowledge from the area can contribute to practical problem solving and so that data from the problem setting can inform new knowledge in the area. Identifying an appropriate area gives researchers an opportunity to construct a contribution to the literature about that area $\left(C_{A}\right)$. Such explicit positioning in relation to the literature is a prerequisite for contributing new knowledge to extant literature, beyond contributions to practical problem solving $\left(C_{\mathrm{P}}\right)$.

- Distinguish the problem from the research question. The problem setting $(P)$ is a re- 
Table 5: Research Design for Second Publication (Singh et al., 2015)

\begin{tabular}{|c|c|}
\hline Component & Specification \\
\hline $\begin{array}{l}\text { Problem } \\
\text { setting }(P)\end{array}$ & $\begin{array}{l}\text { Rural areas lack requisite access to medical expertise and healthcare } \\
\text { services. Although telehealth solutions can help address this issue, rural } \\
\text { health institutions typically don't have the resources and capabilities } \\
\text { required to adopt them. }\end{array}$ \\
\hline $\begin{array}{l}\text { Area of } \\
\text { concern }(A)\end{array}$ & Organizational path constitution in technological innovation. \\
\hline $\begin{array}{l}\text { Conceptual } \\
\text { framing (F) }\end{array}$ & $\begin{array}{l}\text { Framing related to } A\left(F_{A}\right) \text { : Path dependence theory (Arthur, 1989; David, } \\
\text { 1985). } \\
\text { Framing related to } A\left(F_{A}\right) \text { : Path creation theory (Garud and Karnøe, 2001). }\end{array}$ \\
\hline $\begin{array}{l}\text { Research } \\
\text { method (M) }\end{array}$ & $\begin{array}{l}\text { Theory development based on a longitudinal, qualitative case study of } \\
\text { how a rural health district successfully adopted telehealth as a core part } \\
\text { of its operation over a } 20 \text {-year period. }\end{array}$ \\
\hline $\mathrm{RQ}$ & $\begin{array}{l}\text { How can we understand and explain organizational path constitution in } \\
\text { technological innovation? }\end{array}$ \\
\hline Contribution (C) & $\begin{array}{l}\text { Contribution to } \mathrm{A}\left(\mathrm{C}_{\mathrm{A}}\right) \text { : A detailed empirical account of organizational path } \\
\text { constitution that explains how a rural health district adopted and } \\
\text { leveraged telehealth over a } 20 \text {-year period. } \\
\text { Contribution to } \mathrm{FA}\left(\mathrm{C}_{\mathrm{F}}\right) \text { : A theory of how organizations constitute } \\
\text { technological innovation paths. }\end{array}$ \\
\hline
\end{tabular}

al-world phenomenon, while the area of concern $(A)$ is part of the academic literature. Although the two must relate to each other, they are quite distinct entities with different foci. The problems that drive contributions to practice $\left(C_{P}\right)$ are therefore different from the research questions that drive contributions to academic literature $\left(C_{A}\right)$. As such, each problem setting can drive engaged scholarship into several different research questions.

- Design research around a research question. The different components of a research design must align and form a coherent whole. By placing their re- search question at the core of the design, as illustrated in Figure 2, researchers can ensure that it relates to both the problem setting $(P)$ and the area of concern $(A)$, that it can be addressed through the conceptual framing (F) and research method (M), and that it allows for the full development of the suggested contributions (C).

- Develop contributions to both theory and practice. Engaged scholarship serves the dual goal of contributing to practical problem solving $\left(C_{p}\right)$ while also contributing new knowledge to the literature $\left(C_{A}\right)$. Depending on their relationship to the problem setting, researchers should adopt an appropriate form of engaged scholarship and design a resulting publication that delivers both types of contributions.

- Make publication part of a conversation. Each publication aims to engage particular groups of researchers or practitioners in conversations about issues of interest and relevance. Target journals should be chosen with that purpose in mind, and researchers should design their publication as an explicit part of a specific academic or professional conversation.

- Shape the publication through iterative interactions. The development of a coherent and persuasive publication is a creative process that requires an iterative approach. By developing different representations of the publication and by engaging others in reading and commenting on them, researchers stimulate the creative process and facilitate convergence toward a publishable and defendable outcome.

- Play with the basic ideas. By deconstructing already published quality papers and identifying the components of the presented research, researchers can explicate the underlying research design and the structure of the published argument as inspiration for designing their own research into a compatible publication. Such a process of critically explicating the underlying research design and argumentation structure in quality publications can help researchers adopt the principles articulated here to contribute to theory and to the solution of real-world problems.

Acknowledgements. I would like to thank Mike Chiasson and Matt Germonprez for our research collaboration on style composition in action research publication (Mathiassen et al., 2012). I have adapted and used core concepts and ideas from that research as the basis for this essay. I also would like to thank the many colleagues and doctoral students with whom I have conducted workshops to develop and publish engaged scholarship. These experiences helped me formulate the presented design approach to engaged scholarship publication. Also, several of these colleagues provided valuable feedback on earlier versions of the essay. 


\section{REFERENCES}

Alvesson, M. and Sandberg, J. 2011. Generating research questions through problematization. Academy of Management Review 36(2): 247-271.

Amabile, T. M., Patterson, C., Mueller, J., Wojcik, T., Kramer, S. J., Odomirok, P. W., and Marsh, M. 2001. Academic-practitioner collaboration in management research: a case of crossprofession collaboration. Academy of Management Journal 44(2): 418-431.

Arthur, W. 1989. Competing technologies, increasing returns, and lock-in by historical events. The Economic Journal 99(394): 116-31.

Bartunek, J. M. and Louis, M. R. 1996. Insider-Outsider Team Research. Thousand Oaks, CA: Sage.

Boland, R. J. and Collopy, F. (Eds.) 2004. Managing as Designing. Stanford, CA: Stanford University Press.

Boland, R. J., Collopy, F., Lyytinen, K., and Yoo, Y. 2008. Managing as designing: Lessons for organizational leaders from the design practice of Frank O. Gehry, Design Issues 24(1): 10-25.

Checkland, P. 1991. From framework through experience to learning: The essential nature of action research. In H. E. Nissen, H. K. Klein, and R. A. Hirschheim (Eds.). Information Systems Research: Contemporary Approaches and Emergent Traditions: 397-403. Amsterdam, Holland: North-Holland.

Cohen, M. D., March, J. G. and Olsen, J. P. 1972. A garbage can model of organizational choice. Administrative Science Quarterly 17(1): 1-25.

David, P. A. 1985. Clio and the economics of qwerty. American Economic Review 75(2): 332-37.

Day, R. A. 1971. How to Write and Publish a Scientific Paper. IEEE Transactions on Scientific Writing 20(1): 32-7.

Day, R. A. 1991. How to Write and Publish a Scientific Paper. Cambridge, UK: Cambridge University Press.

Edmondson, A. C. 2011. Crossing boundaries to investigate problems in the field: An approach to useful research. In Mohrman, S. A. and Lawler, E. E. (Eds.). Useful Research: Advancing Theory and Practice. San Francisco, CA: Berrett-Koehler Publishers.
Frisk, J. E., Lindgren, R., and Mathiassen, L. 2014. Design matters for decision makers: Discovering IT investment alternatives. European Journal of Information Systems 23: 442-61.

Garud, R. and Karnøe, P. 2001. Path Dependence and Creation. Mahwah, NJ: Lawrence Erlbaum.

Gersick, C. J. G. 1991. Revolutionary change theories: A multilevel exploration of the punctuated equilibrium paradigm. Academy of Management Review 16(1): 10-36.

Glaser, B. G. and Strauss, A. L. 1977. The Discovery of Grounded Theory: Strategies for Qualitative Research. Chicago, IL: Aldine Publishing.

Golden-Biddle, K. and Locke, K. 2007. Composing Qualitative Research. Thousand Oaks, CA: Sage Publications.

Gopen, G. D. and Swan, J. A. 1990. The science of scientific writing - If the reader is to grasp what the writer means, the writer must understand what the reader needs. American Scientist 78: 550-58.

Gregor, S. 2006. The nature of theory in information systems. MIS Quarterly 30(3): 611-42.

\section{Huff, A. S. 1999. Writing for Scholarly}

Publication. Thousand Oaks, CA: Sage Publications.

Langley, A., Smallman, C., Haridimos, T., and Van de Ven, A. H. 2013. Process studies of change in organization and management: Unveiling temporality, activity and flow. Academy of Management Journal 56(1): 1-13.

Locke, K. and Golden-Biddle, K. 1997. Constructing opportunities for contribution: Structuring intertextual coherence and 'problematizing' in organizational studies. Academy of Management Journal 40(5): 1023-1062.

McKay, J. and Marshall, P. 2001. The dual imperatives of action research, Information Technology \& People 14(1): 46-59.

Mathiassen, L., Chiasson, M., and Germonprez, M. 2012. Style composition in action research publication. MIS Quarterly 32(2): 347-63.
Mathiassen, L. and Sandberg, A. 2013. How a professionally qualified doctoral student bridged the practice-research gap: $A$ confessional account of collaborative practice research. European Journal of Information Systems 22(4); 475-92.

Mohr, L. 1982. Explaining Organizational Behavior. San Francisco, CA: Jossey-Bass.

Mohrman, S. A. and Lawler, E. E. 2011. Research for theory and practice: Framing the challenge. In Mohrman, S. A. and Lawler, E. E. (Eds.). Useful Research: Advancing Theory and Practice. San Francisco, CA: Berrett-Koehler Publishers.

Newman, M. and Robey, D. 1992. A social process model of user-analyst relationships, MIS Quarterly 16(2): 249-66.

Rottenberg, A. T. and Winchell, D. H. 2005. The Structure of Argument. Boston, MA: Bedford/St. Martin's.

Shepherd, D. A. and Sutcliffe, K. M. 2011). Inductive top-down theorizing. Academy of Management Review 36(2): 361-80.

Simon, H.A. 1962. The architecture of complexity. Proceedings of the American Philosophical Society 106(6): 467-82.

Simon, H.A. 1996. The Sciences of the Artificial (3rd ed.). Cambridge, MA: The MIT Press.

Singh, R., Mathiassen, L., Astapova, E., and Stachura, M. 2010. Sustainable rural telehealth innovation: A public health case study. Health Services Research 45(4): 985-1004.

Singh, R., Mathiassen, L. and Mishra, A. 2015. Organizational path constitution in technological innovation: Evidence from rural telehealth, MIS Quarterly 39(3): 643-665.

Van de Ven, A. H. 2007. Engaged Scholarship: A Guide for Organizational and Social Research, Oxford, UK: Oxford University Press.

Yin, R. 2009. Case Study Research: Design and Methods. Thousand Oaks, CA: Sage. 


\section{ABOUT THE AUTHOR}

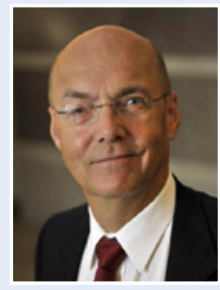

Lars Mathiassen is Georgia Research Alliance Eminent Scholar and professor in Computer Information Systems at Georgia State University, where he also serves as academic director for the Executive Doctorate program at J. Mack Robinson College of Business. His research interests are in digital innovation across different industries. In particular, his research is focused on software engineering, business process innovation, IT-enabled change, and health informatics. His research has been published extensively in journals such as MIS Quarterly, Information Systems Research, IEEE Transactions on Software Engineering, Journal of the Association for Information Systems, IEEE Software, and Communications of the ACM. He is co-author of Professional Systems DevelopmentExperiences, Ideas and Action; Computers in Context-The Philosophy and Practice of Systems Design; Object-Oriented Analysis \& Design; and Improving Software Organizations: From Principles to Practice. He has served as senior editor for MIS Quarterly and currently serves as senior editor for Organization \& Information and Journal of Information Technology. An extensive CV and publication record is available at http://www.larsmathiassen.org/. 